\title{
Assessment of the prevalence of dental anxiety among Palestinian clients attending dental clinics in Bethlehem city: Cross sectional study
}

\author{
Muna Ahmead ${ }^{1}$, Ahmad Rahhal ${ }^{2}$ \\ ${ }^{1}$ Faculty of Public Health, Al-Quds University, Jerusalem, Palestine \\ ${ }^{2}$ Faculty of Dentistry, Arab American University, Jenin, Palestine
}

\section{Email address:}

plorahhal@hotmail.com (A. Rahhal)

\section{To cite this article:}

Muna Ahmead, Ahmad Rahhal. Assessment of the Prevalence of Dental Anxiety among Palestinian Clients Attending Dental Clinics in Bethlehem City: Cross Sectional Study. Psychology and Behavioral Sciences. Vol. 3, No. 6, 2014, pp. 197-202.

doi: $10.11648 /$ j.pbs.20140306.13

\begin{abstract}
Objective: To investigate the prevalence of dental anxiety as well as the relationships between socio-demographic data and perceived dental anxiety among Palestinian clients who attend dental clinics in Palestine. Materials and methods: Participants were recruited into the study from July to August, 2013 from several dental clinics. The modified Corah Dental Anxiety Scale (DAS) was used to measure dental anxiety among the study population. Results: One hundred and sixty four respondents returned the questionnaire after they filled it while in the reception area waiting their turn to see the dentists. Findings reveal that more than one third of the participants experienced a severe level of dental anxiety and were anxious mostly about tooth drilling and local anesthetic injection. Females experienced significantly more dental anxiety than males, but the relationships with other socio-demographic data (including education, place of residency, marital status, and visit habits ) were not significant. Conclusion: This study found high prevalence of dental anxiety which may represent special challenges to the dentists to treat individuals with dental fear. Non of the socio-demographic data except gender revealed statistically significant relation with dental anxiety among the study population Further studies are required to investigate the factors that may lead to increased the prevalence of this phenomena among the Palestinian clients.
\end{abstract}

Keyword: Dental Anxiety, Prevalence, Cross Sectional Study, Socio-Demographic Variables

\section{Introduction}

Today anxiety disorders are among the most common psychiatric disorders.(1) Terms for anxiety emerged in the $12^{\text {th }}$ century and only in the $19^{\text {th }}$ century was the word 'anxiety' used as a psychopathological term.(2) Anxiety was defined as 'a state of tension and expectation of disaster' (3) and the clients may develop phobia. The Diagnostic and Statistical Manual (DSM) of the American Psychiatric Association (1994) defines phobia as a persistent and irrational fear of a specific object, activity or situation that results in the desire to avoid that object, activity or situation(4).

Dental phobia is recognized as a severe form of anxiety that occurs as a result of a dental visit and is associated with stress that triggers excessive or unreasonable anxiety in proportion to the actual threat (5). Many clients consider dental anxiety as highly problematic because of the anticipated pain $(6,7)$ and this is associated with traumatic childhood dental experiences $(8,9)$ The patient may develop symptoms of restlessness, tension, tachycardia and dyspnea. As a consequence, patients may avoid dental care, have irregular dental attendance, or exhibit poor cooperation with dentists (10) despite the use of modern and advanced technologies in the treatment and the management of dental problems (11).

A number of dental anxiety questionnaires have been developed to measure dental anxiety and the most common one is Corah Dental Anxiety Scale (DAS) (12). This scale is considered to be a simple, valid and reliable instrument $(10,11)$. Modification of the original Corah Dental Anxiety Scale was done by Humphoris and Lindsay by adding an extra item referring to respondents' feelings toward local anesthetic injection in the mouth (13) which is utilized in the current study. 
In Palestine, most of the dental services are provided in private dental clinics and outpatients clinics and there is no dental hospital. There is a lack of studies on the prevalence of dental anxiety in this context.

The present study aimed to assess the prevalence of dental anxiety as well as the effect of various socio-demographic variables on dental anxiety of clients who attended several dental clinics in Palestine.

\section{Materials and Methods}

This study was carried out in several clinics in Palestine. The questionnaires were distributed to the patients in the reception area to fill in while they were waiting to see their dentist and the purpose of the study was explained to each participant. Also an information sheet was attached to each questionnaire and endorsed the right of the subject not to participate. Consent was implied by the return of the questionnaire

The questionnaire consisted of two parts: the first part had items on socio-demographic characteristics such as age, gender, marital status, education, and place of residency whereas the second part assessed dental anxiety and was measured using the DAS, which is a five-item instrument inquiring the respondents to answer the following questions:

$1=$ If you went to your dentist for treatment tomorrow, how would you feel?

$2=$ If you were sitting in the waiting room, how would you feel?

3 = If you were about to have a tooth drilled, how would you feel?

4 = If you were about to have your teeth scaled and polished, how would you feel?

$5=$ If you were about to have a local anesthetic injection in your gum, how would you feel?

Each item has five scores ranging from not anxious to extremely anxious in ascending order from one to five. The scores for each of the 5 item responses were summed up to give the final dental anxiety scores for each individual range from 5 to $25(3,11)$.

Dental anxiety level was measured by calculating the sum of individual scores and divided them into 4 groups: $0-8=$ no anxiety, $1-9=$ moderate anxiety, $9-12=$ high anxiety and $15-$ $25=$ severe anxiety (phobia).

Socio-demographic variables were categorised as follows: age $(1=10-20,2=21-30,3=31-40,4=>50)$, education $(1=$ $<=9,2=10-12$ years, and $3=>12$ years $)$, gender $(1=$ male, 2 $=$ female), place of residency $(1=$ city, $2=$ village, $3=$ refugee camp), marital status ( $1=$ single, $2=$ married, $3=$ other (e.g. divorced, widowed), first dental visiting ( $1=$ no, $2=$ yes $)$ and anxiety level $(0=$ no anxiety, $1=$ moderate anxiety $3=$ high anxiety and $4=$ severe anxiety (phobia).

The questionnaire was in English and translated into Arabic by the researchers. The validity of the translation was checked by a committee of 5 experts who hold Ph.D in dentistry, psychology, psychiatric and mental health. The final version was back translated into English by interpreter
All the data collected were entered into spreadsheets, and SPSS software version 15.0 was used for statistical analysis. Descriptive frequencies were calculated for sociodemographic variables, and the chi-square test used to analyze the relationship between socio-demographic data and dental anxiety.

\section{Results}

Two hundred questionnaires were distributed and one hundred and sixty four questionnaires were returned which accounts for a response rate of 82 percent. Table 1 show the socio-demographic and background characteristics of the participants.

Data in table 1 shows that the majority of the respondents were females $(62.2 \%)$ and married (70.15). Half of the participants lived in the city, one third lived in rural villages and the remaining lived in refugee camps. A large proportion of the sample $(84.7 \%)$ had over 10 years education. The majority had visited the dentists previously $(87.2 \%)$.

Table 1. Socio demographic variables and dental visiting practices of the study population

\begin{tabular}{|c|c|c|c|}
\hline Variables & & Number & Percentage \\
\hline \multirow[t]{5}{*}{ Age } & $10-20$ & 13 & 7.9 \\
\hline & $21-30$ & 62 & 37.8 \\
\hline & $31-40$ & 48 & 29.3 \\
\hline & $41-50$ & 31 & 18.9 \\
\hline & $>50$ & 10 & 6.1 \\
\hline \multirow[t]{2}{*}{ Gender } & Male & 62 & 37.8 \\
\hline & Female & 102 & 62.2 \\
\hline \multirow[t]{3}{*}{ Marital status } & Single & 41 & 27.5 \\
\hline & Married & 115 & 70.1 \\
\hline & $\begin{array}{l}\text { Others (widowed } \\
\text { and divorced) }\end{array}$ & 4 & 2.4 \\
\hline \multirow[t]{3}{*}{ Education } & $\leq 9$ years & 25 & 15.2 \\
\hline & $10-12$ years & 56 & 34.1 \\
\hline & $>12$ years & 83 & 50.6 \\
\hline \multirow[t]{3}{*}{ Place of residency } & City & 82 & 50 \\
\hline & Village & 50 & 30.5 \\
\hline & Camp & 32 & 19.5 \\
\hline \multirow{2}{*}{$\begin{array}{l}\text { Is this the first visit } \\
\text { to the dentist? }\end{array}$} & Yes & 21 & 12.8 \\
\hline & No & 143 & 87.2 \\
\hline
\end{tabular}

\section{Dental Anxiety}

Table 2 shows that only 4 persons (2.4\%) claimed that they would be very anxious if they visited the dentist the next day, more than one third of the respondents $(38.4 \%)$ indicated that they would be a little uneasy about it and one third claimed they would not care one way or the other. The majority of the respondents stated tense feeling for all the other dental anxiety questionnaire items $(31.7 \%, 42.1 \%, 26.2 \%, 44.5 \%$ respectively) and a minority reported that they sometimes broke out in sweat or felt almost physically sick $(3.7 \%, 5.5 \%$, $4.3 \%, 10.4 \%$ respectively). Waiting for the dentist to prepare the drill or anesthetic injection provoked the highest percentage of anxiety responses. Also, the highest percentage of extreme responses related to the question concerning 
waiting for a local anesthetic injection in the gum which showed the highest anxiety scores $(10.4 \%)$.

Table 3 presents the prevalence of dental anxiety among the respondents according to 4 categories (no anxiety, moderate anxiety, high anxiety and severe anxiety according to the total scores of SAD items). This shows that more than one third of the study population (39.5\%) experienced a severe level of anxiety, less than one third reported moderate anxiety $(28.3 \%)$, and $19.5 \%$ claimed to have high anxiety level. Only $12.6 \%$ stated that they experienced no dental anxiety.

In table 4 the prevalence of dental anxiety was explored in relation to other socio-demographic data including age, gender, place of residency, education, and previous dental visits. No significant differences were found for the relation between anxiety levels and demographic variable except gender as shown in table 4

Data reveal that male respondents experienced less dental anxiety than females and 47.1 of females versus 27.4 of males reported severe anxiety. This result was statistically significant (chi-square $=15.46, \mathrm{df}=3, \mathrm{p}=0.001$ ). Chi squared analysis revealed no significant differences for age, marital status, place of residency, education and visit habit.

Table 2. Prevalence of dental anxiety among study population

\begin{tabular}{|c|c|c|}
\hline Items & Frequency & Percentage \\
\hline \multicolumn{3}{|l|}{ If you went to your dentist for treatment tomorrow } \\
\hline I would look forward to it as a reasonably enjoyable experience & 13 & 7.9 \\
\hline I wouldn't care one way or the other. & 54 & 32.9 \\
\hline I would be a little uneasy about it. & 63 & 38.4 \\
\hline I would be afraid that it would be unpleasant and painful & 30 & 18.3 \\
\hline So anxious that I sometimes break out in a sweat or almost feel physically sick & 4 & 2.4 \\
\hline \multicolumn{3}{|l|}{ Waiting at the dental clinic for your turn } \\
\hline Relaxed & 46 & 28 \\
\hline A little uneasy & 43 & 26.2 \\
\hline Tense & 52 & 31.7 \\
\hline Anxious & 17 & 10.4 \\
\hline So anxious that I sometimes break out in a sweat or almost feel physically sick & 6 & 3.7 \\
\hline \multicolumn{3}{|l|}{ In the dentist chair waiting for drill to be used } \\
\hline Relaxed & 23 & 14 \\
\hline A little uneasy & 30 & 18.3 \\
\hline Tense & 69 & 42.1 \\
\hline Anxious & 33 & 20.1 \\
\hline So anxious that I sometimes break out in a sweat or almost feel physically sick & 9 & 5.5 \\
\hline \multicolumn{3}{|l|}{ In the dentist chair waiting to have your teeth cleaned } \\
\hline Relaxed & 84 & 29.3 \\
\hline A little uneasy & 43 & 26.2 \\
\hline Tense & 43 & 26.2 \\
\hline Anxious & 23 & 14 \\
\hline So anxious that I sometimes break out in a sweat or almost feel physically sick & 7 & 4.3 \\
\hline \multicolumn{3}{|l|}{ In the dentist chair waiting to have a local anesthetic injection in the gum? } \\
\hline Relaxed & 17 & 10.4 \\
\hline A little uneasy & 37 & 22.6 \\
\hline Tense & 73 & 44.5 \\
\hline Anxious & 20 & 12.2 \\
\hline So anxious that I sometimes break out in a sweat or almost feel physically sick & 17 & 10.4 \\
\hline
\end{tabular}

Table 3. The prevalence of dental anxiety according to the total scores of SAD items

\begin{tabular}{lll}
\hline & Frequency & Percentage \\
\hline No anxiety & 20 & 12.6 \\
Moderate anxiety & 45 & 28.3 \\
High anxiety & 31 & 19.5 \\
Severe anxiety & 38.4 & 39.5 \\
\hline
\end{tabular}

Table 4. The prevalence of dental anxiety in relation with participants'socio-demographic data

\begin{tabular}{llllllll}
\hline Variables & Categories & & No anxiety & Moderate anxiety & High anxiety & Severe anxiety & P value \\
\hline \multirow{4}{*}{ Gender } & \multirow{2}{*}{ Male } & $\mathrm{N}$ & 14 & 22 & 9 & 17 & \\
& & $\%$ & $22.6 \%$ & $35.5 \%$ & $14.5 \%$ & $27.4 \%$ & .0001 \\
& Female & $\mathrm{N}$ & 6 & 25 & 23 & 48 & $47.1 \%$ \\
\hline
\end{tabular}




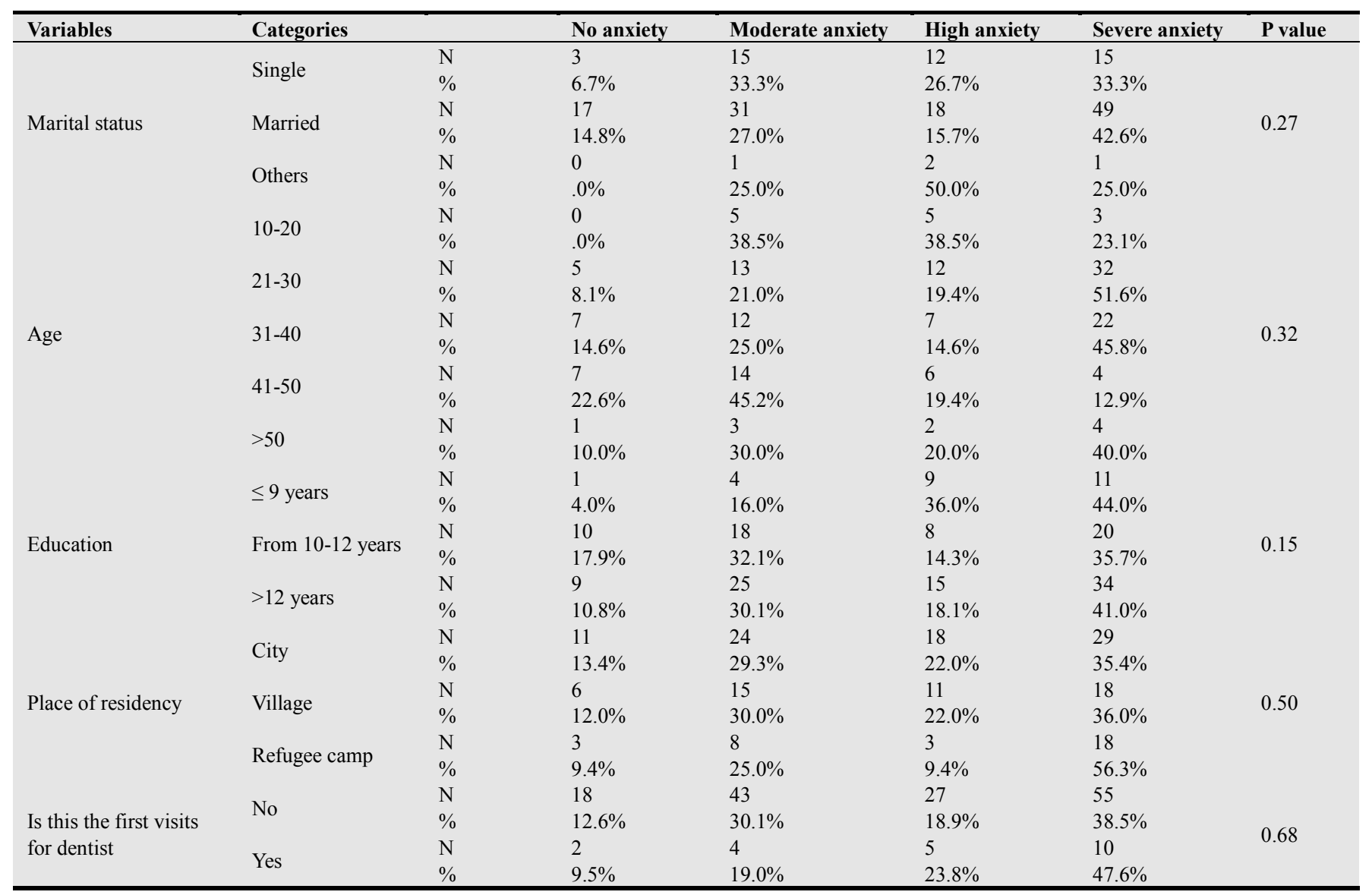

\section{Discussion}

Although, there is a considerable volume of literature concerning dental anxiety, there is a lack of studies in the developing countries (11) particularly Palestine. This study is the first attempt to assess the prevalence of dental anxiety among Palestinian clients. Findings showed that the prevalence of dental anxiety among Palestinian clients is high in comparison with other population. For example, only $12.6 \%$ of the participants stated that they did experience dental anxiety and $39.5 \%$ and $19.5 \%$ of the clients reported having severe and high level of dental anxiety. These percentages are considered high in comparison to the findings of studies from other countries such as UK (3.3$17.4 \%)(11)$, and Norway (4-9\%) (14). Also, unlike the data obtained from the current study which showed more than one third of the study population experienced severe level of anxiety, Kumar found no participants with extremely high dental anxiety (11) and Eitner reported $4.6 \%$ had a DASscore $\geq 15$ (highly anxious/phobic) and $8 \cdot 6 \%$ had high level of anxiety (DAS-scores of 13 or 14) (15).

The majority of the respondents reported tense feeling for all the dental anxiety questionnaire items (DAS) and few reported that they sometimes broke out in sweat or felt almost physically sick. The severe dental anxiety was mostly associated with drilling and the use of local anesthetic injection which provoked the highest percentage of tense feeling. These findings are consistent with the findings of other studies that found injection and drilling to be the major sources of dental fear $(10,16)$ and in disagreement with study by Kumar et al (11).

Given the lack of studies in Palestine, these differences could be attributed to the unstable political situation and the poor economic status of the Palestinian people which may increase the level of anxiety in general. We do not have an evidence from the present study about the factors that may increase the prevalence of dental anxiety among the study population but previous studies indicated that there is a direct link between dental anxiety and general anxiety disorder (16). Also it is found that participants with dental anxiety had more symptoms of general anxiety and depression than did participants without dental anxiety.(16) According to the World Health Organization report, the prevalence of posttraumatic stress, anxiety, mood and somatoform disorders among Palestinian people is $40.3 \%$ among the $59 \%$ of the population that had been directly exposed to violence, and the majority has high level of stress (17). Moreover, other studies reported a high prevalence of emotional (36.3\%) and behavioural $(34.9 \%)$ problems, and moderate-to-severe PTSD (39.5\%) among young Palestinian people. (18)

In addition, there is a lack of educational courses or information about dental anxiety at the Palestinian universities. For example, students who study other sciences than dentistry had higher level of severe anxiety than dental students because of inadequate dental health education. (10). Also Palestinian media and dentists may not provide enough 
information about this subject to the public in order to increase their awareness.

The risk of a high prevalence of severe dental anxiety (phobia) is that it may delay dental treatment and may lead to deterioration of dental health (19). So dentists are required to strengthen their relation with their clients, educate them about dental anxiety and explain what they are doing and provide social support. Also there is a need to change dental practice by adopting less threatening technology such as lasers (20). Further studies or trials are required to investigate the effectiveness of these strategies in reducing dental anxieties.

Geographic areas and demographic data are associated with dental anxiety and they may affect the utilization of dental services (21). Previous studies showed higher level of dental anxiety among married patients than the unmarried and divorced patients (24), participants from urban areas than those in rural areas, (21) people with low education level than people with higher education (25). So socio-demographic data including age, gender, place of residency, education, and dental visits habits were examined in relation to the level of anxiety in the present study. However, age, gender, place of residency, education, and dental visits habits were statistically not significant and only the gender variable was statistically significant.

In the present population, more than half of the respondents were females $(62.2 \%)$. Females use more dental services and consider dental care more important than males (21). Similar to the findings obtained from other studies (10), male respondents experienced less dental anxiety than females and $47.1 \%$ of females versus $27.4 \%$ of males reported severe dental anxiety. This finding is expected as previous research showed that in general women have high level of general anxiety than men (22).

Several limitations of the current study are worth mentioning. First, this study utilized a cross-sectional design, which may raise concerns about generalizing the findings, since it evaluated the situation at a particular point in time. Second, the data collection for this study relied solely on a self-reported questionnaire so the results may not be completely reliable

Finally, the instrument used in this study had not been previously tested in the context of Palestinian culture. However, a focus group including experts were consulted and approved the content, clarity and relevance of the instrument.

\section{Conclusion}

This study reveals high prevalence of dental anxiety among the Palestinian clients and gender was the only significant variable that has a relation with dental anxiety among the study population. The results suggest that there is a need for further research to identify the factors that may influence this phenomenon. More effort should be made to treat dental anxiety in order to encourage the patients to seek dental care and treatment.

\section{Acknowledgments}

The authors would like to acknowledge the assistance of $\mathrm{Dr}$ Peter Power at the NPCRDC, University of Manchester, UK, Dr Mai Maghatheh and Dr Elias Dabeet in writing this article.

\section{References}

[1] Ameringen, M. V, Mancini, C, Farvolden, P (2003) The impact of anxiety disorders on educational achievement. Anxiety Disorders 17(5), 561-571

[2] Himmelhoch, J, Levine, J, and Gershon, S (2001) Historical overview of the relationship between anxiety disorders and affective disorders. Depression and Anxiety 14(2), 53-66

[3] Wolman, B. B and Stricker, G (1994) Anxiety and related disorders: a handbook. $1^{\text {st }}$ ed. New York: John Wiley and Sons

[4] American Psychiatric Association (2000) Diagnostic and Statistical Manual of Mental Disorders. $4^{\text {th }}$ ed, text version. Washington DC: American Psychiatric Association

[5] Kent GG (1984) The Psychology of Dental Care. Wright, Bristol, 45

[6] Green A, Green RM (1989) Attitudes of some young female bank employee to dentistry. J Dent $17,68-71$

[7] Friis-Hasche E (1990) Pediatric dentistry and dental fear. Tandlaegebladet 94, 70-73

[8] Skaret E, Raadal M, Berg E, Kvale G (1998) Dental anxiety among 18 -yr-olds in Norway. Prevalence related factors. Eur J Oral Sci 106, 835-843

[9] Firat D, Tunc EP, Sar V (2006) Dental Anxiety Among Adults in Turkey. J Contemp Den Pract 7(3):75-82

[10] Al Omari, W, Al Omari M, Dental anxiety among university students and its correlation with their field of study. J appl Oral Sci 17(3), 199-20

[11] Kumar S, Bhargav P, Patel A, Bhati M, Balasubramanyam G, Duraiswamy P, Kulkarni S. Does dental anxiety influence oral health-related quality of life? Observations from a crosssectional study among adults in Udaipur district, India. ( 2009) J Oral Sci 51(2):245-54

[12] Corah NL (1969) Development of a dental anxiety scale. J Am Dent Assoc 48, 596

[13] Humphris GM, Morrison T, Lindsay SJ (1995) The modified dental anxiety scale: validation and United Kingdom norms. Community Dent Health 12,143-50

[14] Schuller AA, Willumsen T, Holst D (2003) Are their differences in oral health and oral health behavior between individuals with high and low dental fear? Community Dent Oral Epidemiol 31, 116-121.

[15] Eitner S, Wichmann M, Paulsen, Holst A (2006) Dental anxiety-an epidemiological study on its clinical correlation and effects on oral health. J Oral Rehab 33 (8), 588 - 593

[16] Kaakko T; Milgrom P; Coldwell S E; Getz T; Weinstein P; Ramsay D S (1998) Dental fear among university employees: implications for dental education.Journal of dental education 62(6), 415-20 
[17] World Health Organization (2006) Fifty-Ninth world health assembly. Health conditions in the occupied Palestinian territory, including east Jerusalem, and in the occupied Syrian Golan: progress report

[18] Miller T, El-Masri M, Allodi F, Quota S (1999) Emotional and behavioural problems and trauma exposure of school-aged Palestinian children in Gaza: some preliminary findings, Medicine. Conflict and Survival 15:368-78

[19] Berggren U, Meynert G (1984) Dental fear and avoidance: causes, symptoms, and consequences. J Am Dent Assoc 109, $247-251$

[20] Smith TA, Heaton LJ (2003) Fear of dental care: are we making any progress? J Am Dent Assoc 134(8), 1101-8

[21] Lisa J. Heaton, Timothy A. Smith, Ted P. Raybould (2004) Factors Influencing Use of Dental Services in Rural and Urban Communities: Considerations for Practitioners in Underserved Areas . J Dent Educ. 68(10), 1081-1089
[22] Sinan AY, Özdemir D, Öztürk M, Polat S(2002) An Assessment of dental anxiety in oral surgery patients Gülhane Tip Dergisi 44 (4), 395 - 398

[23] Hägglin C, Hakeberg M, Ahlqwist M, Sullivan M, Berggren U (2000). Factors associated with dental anxiety and attendance in middle aged and elderly women. Community Dent Oral Epidemiol 28(6), 451-60

[24] Fábián TK, Kelemen P, Fábián G (1998 ).Introduction of the concept of Dental Anxiety Scale in Hungary. Epidemiologic studies on the Hungarian population. Fogorv Sz 91(2):43-52

[25] Albert H.B. Schuurs, Hugo-J. Duivenvoorden, Sljo K. Thoden van Velzen, Frans Verhage, Mlchiel A.J. Eijkman, Peter C. Makkes (2006). Sociodemographic correlates of dental anxiety. Community Denti Oral Epidemiol 13 (4), 212 - 215 